\title{
ORIGINAL ARTICLE \\ Versatility of Reverse Sural Artery Flap for Coverage of Heel and Proximal Foot Defects in Children
}

\author{
MUHAMMAD ANWAR ${ }^{1}$, FAISAL WAHEED ${ }^{2}$, KHADIJA HUSSAIN ${ }^{3}$ \\ ${ }^{1}$ Professor \& Head, Department of Plastic Surgery, Sheikh Zayed Medical College/Hospital, Rahim Yar Khan. \\ ${ }^{2}$ Assistant Professor Department of Plastic Surgery, Sheikh Zayed Medical College/Hospital, Rahim Yar Khan. \\ ${ }^{3}$ Medical Officer Department of Plastic Surgery, Sheikh Zayed Medical College/Hospital, Rahim Yar Khan. \\ Correspondence to : Faisal Waheed, E-mail: drfaisal_nmc@yahoo.com, Cell: 0300-7229229
}

\begin{abstract}
Objective: The objective of the study was to determine the versatility of reverse sural artery flap in terms of its reliability and efficacy for reconstruction of soft-tissue defects of heel and proximal foot in children.

Material and Methods: A total of 30 patients aged 5-13 years with ankle and foot defects admitted to the Plastic Surgery and Burn department at the Sheikh Zayed Hospital, Rahim Yar Khan from January 2018 to July 2020 were studied by designing a retrospective cross-sectional case series study.

Results: Out of 30 flaps, $26(86.7 \%)$ healed fully, whereas $4(13.3 \%)$ complicated by partial necrosis requiring a secondary procedure. Nineteen (63.3\%) patients had wheel spoke injuries, eight $(26.6 \%)$ sustained degloving injury after a road traffic accident, and three $(0.1 \%)$ patients were having a history of electric burn. In 22 patients an interpolated flap was used and in 8 cases an islanded flap. Donor sites were skin grafted in all patients. Two patients developed hypertrophic scarring at donor area. All patients showed good functional results, however flap remained insensate throughout the follow-up period that was minimum for 6 months.

Conclusion: The reverse sural artery flap is versatile, reliable and a method of choice in reconstructing softtissue defects of the hind foot in children. This flap is easy to dissect, has robust blood supply and does not sacrifice any major blood vessel of the leg.
\end{abstract}

Key Words: Reverse Sural Artery Flap, children, Ankle and Foot, Soft-tissue Defects, Wheel Spook Injury

\section{INTRODUCTION}

Soft-tissue defects of the proximal foot and heel are considered one of the most challenging defects to reconstruct by the plastic surgeons due to limited local flap options. 1 There are various techniques to cover such defects such as fasciocutaneous flaps, muscle flaps, local transposition flaps, cross-leg flaps, and free flaps. ${ }^{2}$ Although free flap is the promising option to cover such defects, it has various shortcomings including longer operating time, high cost, need for technical microsurgical equipment, and a skilled microsurgical team. ${ }^{3}$ Therefore, the sural flap has been recognized as an acceptable substitute.

The term "sural" is derived from the sural angiosome, suggesting the site from where the skin island of flap is obtained. ${ }^{3}$ Ponten ${ }^{4}$ in 1981 first described the use of proximally based fasciocutaneous flap from the sural angiosome for repair of soft- tissue defects of the lower one third of the leg and foot. Two years later in 1983 Donski and Fogdestam 5 introduced the distally based sural fasciocutaneous flap. In 1992, Masquelet et al. 6 reintroduced the sural flap with its complete and concise description of the relevant anatomy and the surgical procedure. After the work of Masquelet et al. the distally based sural flap has become a method of choice for the reconstruction of lower leg, foot and heel defects.

The median sural artery and the peroneal artery are interconnected via the septocutaneous perforators. There are specific anatomical sites in the lower leg where the perforators from the deep arteries make anastomosis with superficial neuro-cutaneous arteries. The distally based fasciocutaneous sural flap depends upon this

Received on 05-12-2020

Accepted on 05-05-2021 definitive vascular plexus. ${ }^{7}$ Superficially, three structures that supply the sural flap are median sural nerve, sural artery and the small saphenous vein.

Various variants of the sural flap, considering the surgical technique, has been described including; delayed sural flap, fasciomyocutaneous sural flap, distally based sural flap, distally based cross-leg sural flap, distally based sural neurocutaneous flap, distally based sural neurofasciomyocutaneous flap, distally based sural neuro-lesser saphenous veno-fasciocutaneous compound flap, and nerve-sparing distally based sural fasciocutaneous flap. ${ }^{8.9}$ The reverse sural flap in addition to its many advantages is also associated with some complications like venous congestion, partial or total flap failure, ugly looking scar at donor site, and sensory problems. ${ }^{2,3,8}$

In adult patients post-traumatic soft-tissue defects are the main indication but in children the use of this flap has not been well evaluated. The aim of this study was to determine the versatility of reverse sural artery flap in terms of its reliability and efficacy for the coverage of proximal foot and heel defects in children.

\section{METHODS}

This cross-sectional, case series, study was carried out at department of plastic surgery and burn, Sheikh Zayed Hospital, Rahim Yar Khan from January 2018 to July 2020. A total of 30 pediatric patients were managed using Reverse Sural Artery Flap (RSAF). This was retrospective study and inclusion criteria were patients upto 15 years of age having no comorbid conditions. Patients with incomplete data, or who lost to follow-up were excluded. After institutional review board approval, patients' data were collected on a proforma from previously recorded history, clinical examination, operative findings and outcome. Demographic data, etiology, site and defect size, 
flap survival or failure, and functional outcome in terms of walking/weight bearing and flap durability were noted. All children had defect on heel and proximal foot with exposed Achilles' tendon, calcaneal bone, or loss of heel pad.

Surgical Technique: The flap design was marked on the skin along the course of median sural nerve using handheld Doppler (Fig.1). The pivot point was marked $5 \mathrm{~cm}$ above the lateral malleolus which is the landmark of a constant and the most significant perforator originating from the peroneal artery to supply the RSAF. The median sural nerve, accompanied by small saphenous vein and sural artery, course was marked between two heads of gastrocnemius muscle. The defect size was measured using a gauze piece and transposed on the calf to mark the skin pedal. Patient was kept in the prone position and a tourniquet was applied during the procedure. Flap was elevated with identification and ligation of saphenous vein and sural nerve. The dissection was carried out from proximal to towards distal end. After complete elevation the flap was rotated $180^{\circ}$ and secured to the wound. During the early postoperative period flaps were observed periodically for signs of venous congestion through a window in the dressing. The RSAF was designed as interpolated or islanded flap and pedicle width was kept at least $4 \mathrm{~cm}$ to minimize venous congestion. The donor area was skin grafted.

\section{RESULTS}

Patients' age ranged from 5 - 13 years and the average age was 8 years. Twenty-two (73.3\%) patients were male and $8(26.7 \%)$ were female. Male to female ratio was 2.7:1. Nineteen $(63.3 \%)$ patients had wheel spoke injuries, 8 $(26.7 \%)$ sustained degloving injury after a road traffic accident, and $3(0.1 \%)$ patients were having a history of electric burn. Fifteen (50\%) children had partial or complete loss of heel pad. In 2 cases ankle joint was open with fracture of lateral malleolus; one patient had cut Achilles tendon. In 5 patients Vacuum Assisted Closure (VAC) dressing was applied for 5 days before flap coverage. In 8 patients an islanded flap was used and in 22 patients interpolated flap. Donor sites were resurfaced with skin graft in all the patients. Defect size varied from $3.5 \times 5 \mathrm{~cm}$ $8 \times 7 \mathrm{~cm}$. Most of the cases were operated after 5-7 days because of delayed presentation or referral from other departments. No case of total flap failure was seen. Partial flap necrosis was noticed in 4 (13.3\%) cases. In 2 cases there were marginal necrosis that was debrided and flap margins re-stitched. In one case necrosed tissue was excised and flap was advanced. In $4^{\text {th }}$ patient skin graft was applied after debriding the necrosed portion of the flap. Two patients developed mild hypertrophic scarring at donor area. All the patients showed satisfactory functional outcome in terms of walking/weight bearing and flap durability. However, the flap remained insensate throughout the follow-up period. The minimum follow-up period was 6 months and maximum $1 \frac{1}{2}$ years.

\section{CASE REPORTS}

Case 1: A 10 years old boy presented after a motorbike wheel spoke injury to the right foot after 5 days of injury. He had degloving of posterior ankle, avulsion of heel pad and necrosed skin over the Achilles' tendon (Fig 2, A) After debridement $4 \times 7 \mathrm{~cm}$ defect resulted exposing the calcaneal bone, Achilles' and peroneus tendons (Fig 2, B). The defect was covered with a $7 \times 15 \mathrm{~cm}$ islanded fasciocutaneous RSAF. The donor area and adipofascial flap pedicle were skin grafted. Early postoperative results shows viable flap and after 6 months well healed flap with good results (Fig 2, C-D).

Case 2: A 13-year old boy presented after one week of road traffic accident. He had complete loss of right heel pad and adjacent sole (Fig. 2, A). After debridement there was a $6 \times 8 \mathrm{~cm}$ defect with exposed Achilles' tendon and calcaneal bone (Fig. 2, B). Defect was reconstructed with a $7 \times 18 \mathrm{~cm}$ interpolated fasciocutaneous RSAF (Fig. 2, C). The donor site and the remaining soft tissue defect on medial proximal sole were resurfaced with skin graft. Final outcome after 1-year shows complete heel pad reconstruction and durable results (Fig. 2, D).

Case 3: An 8-year-old boy was referred from pediatric surgery department with a history of wheel spoke injury to the heel of the right foot. After Debridement a defect of $6 \mathrm{x}$ $7.5 \mathrm{~cm}$ with exposed calcaneal bone was covered with a pedicled RSAF. Final result after 6 months shows complete healing of donor site and durable reconstruction of posterior heel pad (Fig. 3, A-B).

Case 4: A 6-year-old girl presented after a history of road traffic accident to the right proximal foot. Patient had a defect of $4.5 \times 5.5 \mathrm{~cm}$ with navicular bone exposed. After thorough wound debridement the defect was covered with a pedicled RSAF. Early results after one weak postoperative showing viable flap and complete coverage of the defect (Fig. 4, A-B).

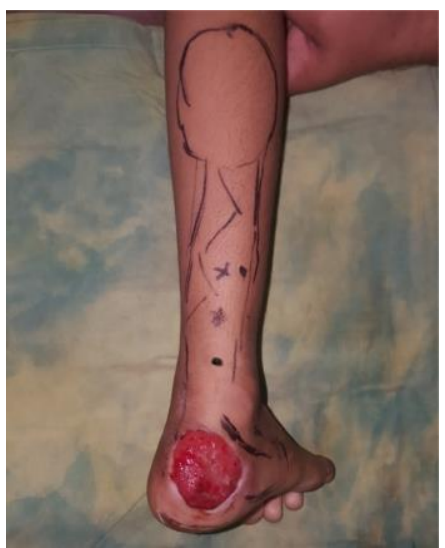

Fig. 1: Reverse Sural Artery Flap Design and Marking

Fig. 2 (Case 1)

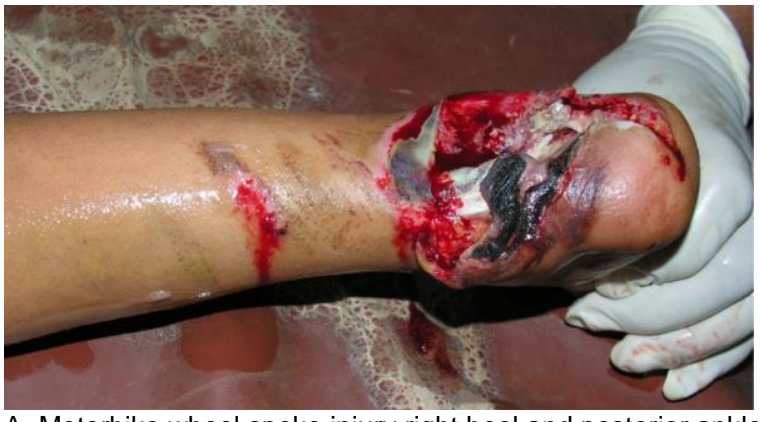

A. Motorbike wheel spoke injury right heel and posterior ankle 


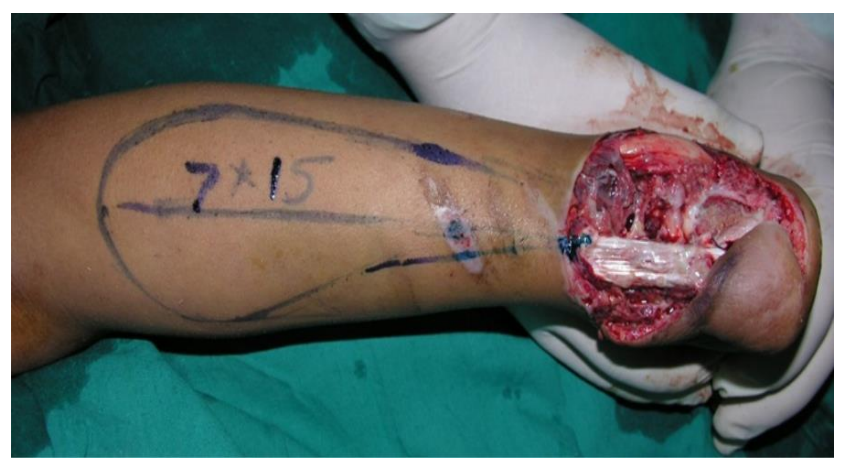

B. After wound debridement calcanian bone, Achilles' and peroneus tendons exposed. Reverse Sural Artery Flap (RSAF) marking for coverage of defect

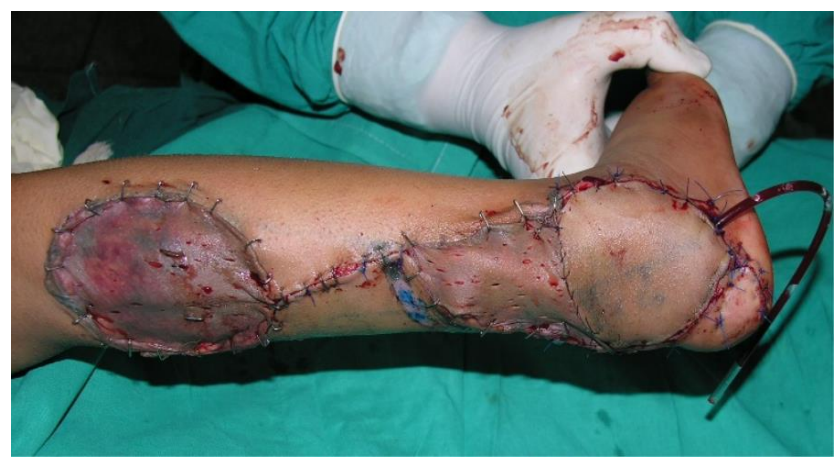

C. Island RSAF was applied to the defect, donor site and flap pedicle were covered with skin graft

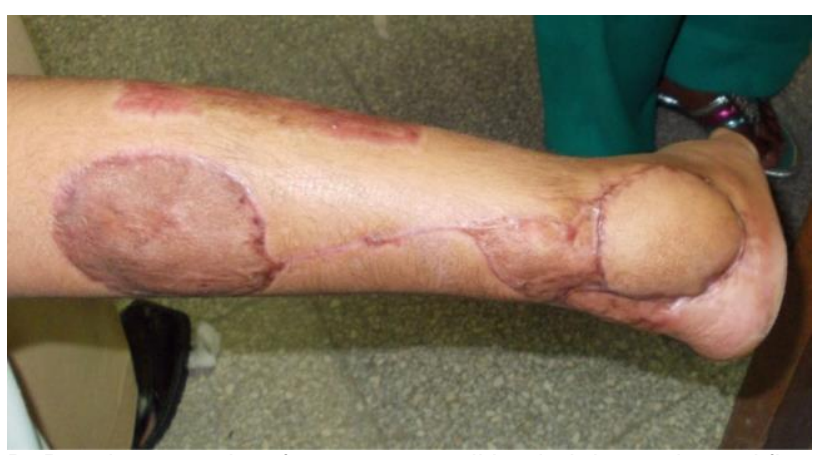

D. Results 8 months after surgery, well healed donor site and flap

Fig. 3 (Case 2)

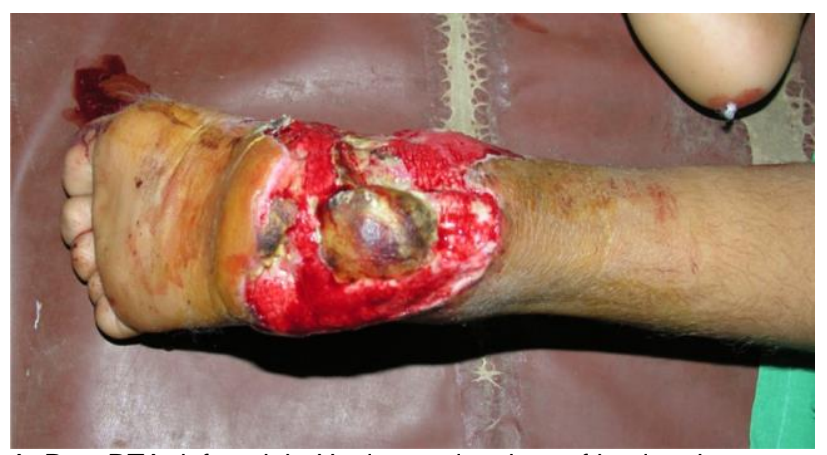

A. Post RTA defect right Heel, complete loss of heel pad.

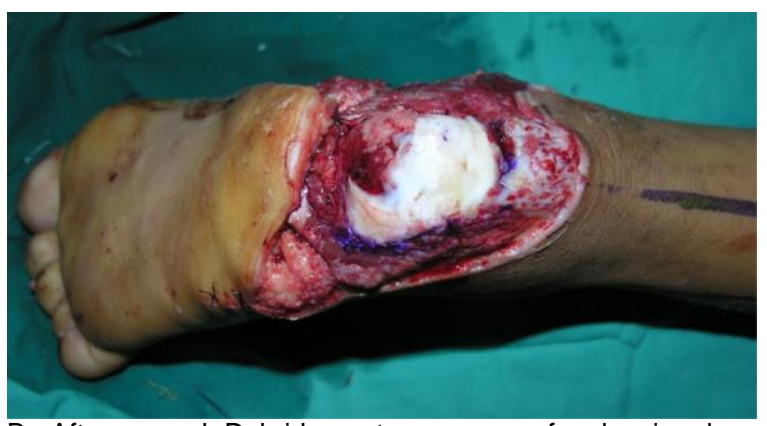

B. After wound Debridement exposure of calcanian bone and Achilles' tendon

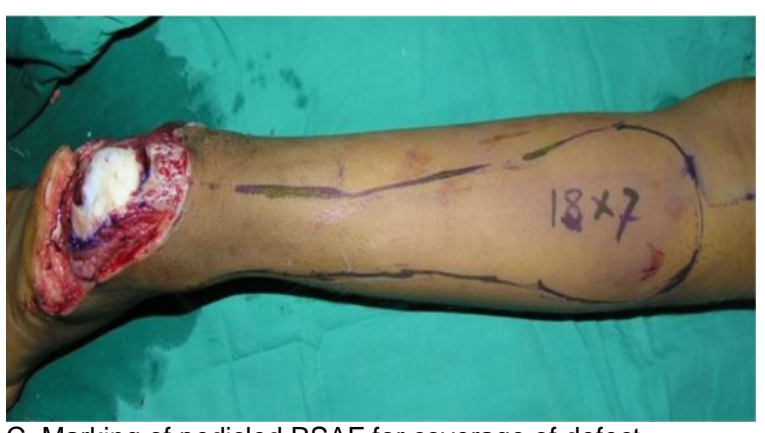

C. Marking of pedicled RSAF for coverage of defect

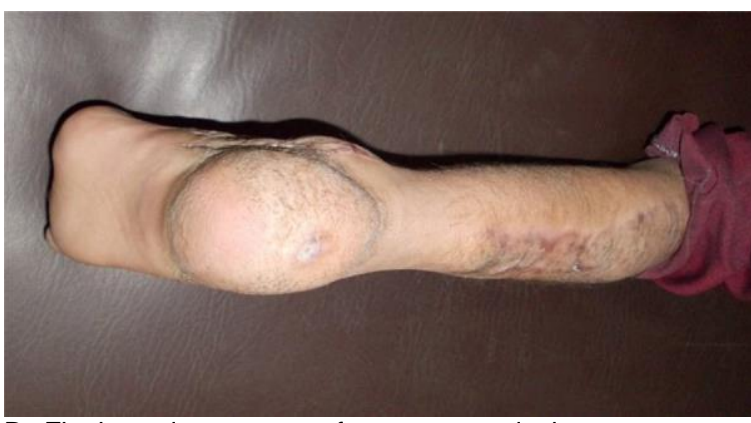

D. Final result one year after surgery, nicely reconstructed hee pad with durable results.

Fig. 4 (Case 3)

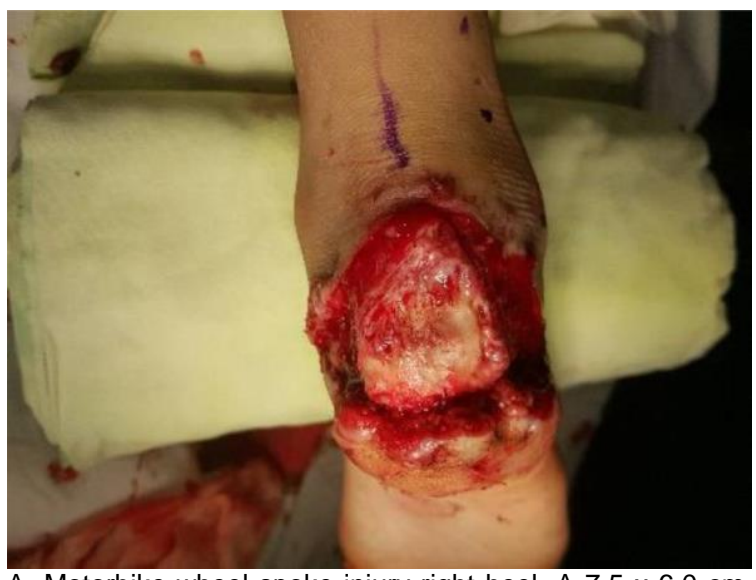

A. Motorbike wheel spoke injury right heel. A $7.5 \times 6.0 \mathrm{~cm}$ defect with exposed calcanian bone. 


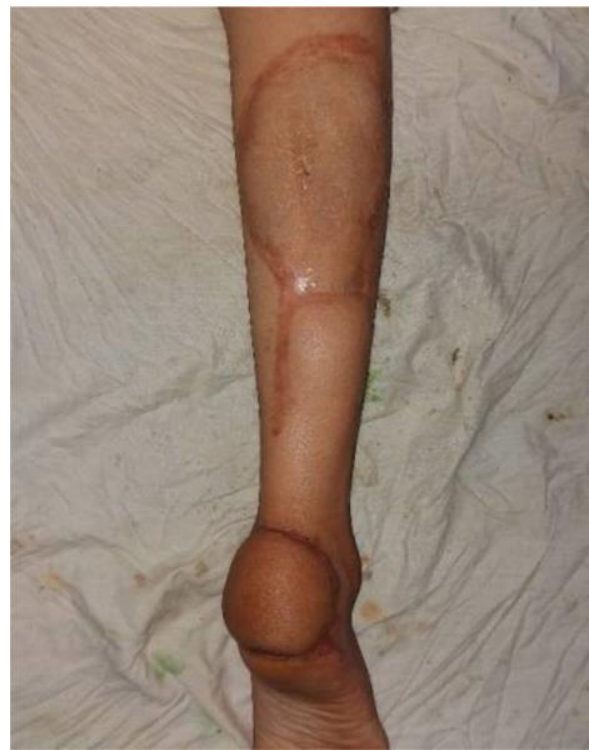

B. Final result 6 months after surgery, well healed donor site and reconstruction of posterior heel pad.

Fig. 5 (Case 4)

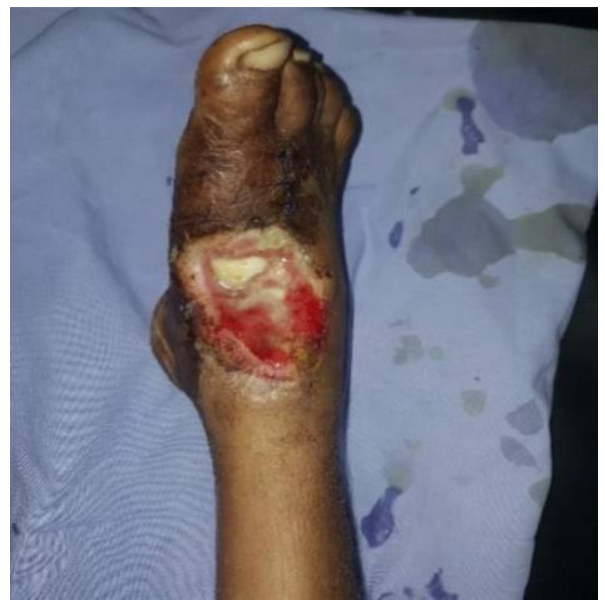

A. Post RTA defect right Proximal foot with exposed navicular bone.

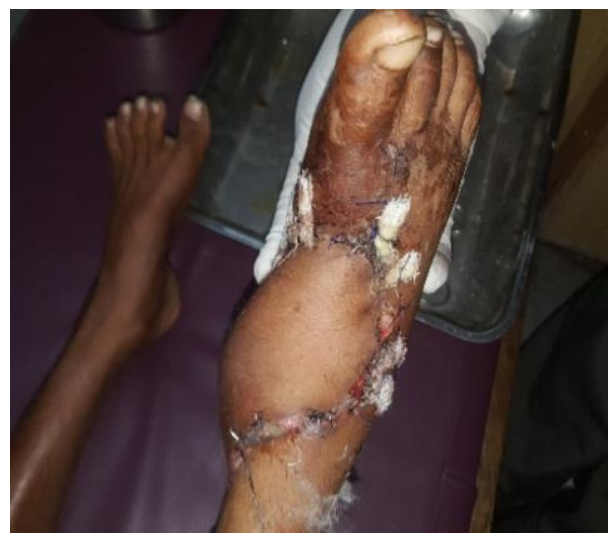

B. One week after surgery, reconstruction of defect with viable RSAF.

\section{DISCUSSION}

In children proximal foot and heel injury is commonly seen in our country because of wearing open type of shoes and riding on the back seat of motorbike and bicycle (pillion riding). ${ }^{10}$ The hind foot is covered by thin skin and even minor trauma can easily expose the underlying tendons and ligaments. Due to lack of excess skin in this area, it is difficult to reconstruct this area using local flaps. 1 Moreover, skin graft can not be applied over exposed tendons, ligaments and bone. Few locoregional flaps for reconstruction of this difficult area have been reported such as medial plantar artery flap, RSAF, and peroneal perforator artery flap. ${ }^{11}$ Free flap is another option but it requires great expertise, long operating time and sophisticated equipment. ${ }^{3}$ After having been described by Ponten ${ }^{4}$ local fasciocutaneous flaps have regained popularity in recent years for reconstruction of hind foot defects. In our study we preferred the RSAF to reconstruct proximal foot and heel defects in children. The few valuable advantages of using this flap include simple and easy dissection technique, comparatively low morbidity at donor area and saving a major artery of the leg. ${ }^{12}$

The sural nerve descends between the two heads of the gastrocnemius and penetrates the deep fascia at the junction of upper and middle-thirds of the leg. The nerve is accompanied by superficial sural artery. In $65 \%$ of people sural artery takes its origin from the popliteal artery while in $20 \%$ of people, it originates from the medial sural artery, and in $8.3 \%$ of people, its origin is from the lateral sural artery. The septo-cutaneous perforators from the peroneal artery make connections with the superficial sural artery which then ultimately supply the reverse sural flap. ${ }^{4,5}$

The distally based fasciocutaneous flaps are supplied in a retrograde fashion by septocutaneous and musculocutaneous perforators of the three main vessels of the leg, the anterior tibial, posterior tibial , and the peroneal artery. ${ }^{8,13}$ These perforators can be localized in the lower leg with the help of hand held doppler at a distance of 2 $\mathrm{cm}, 5 \mathrm{~cm}$, and $10 \mathrm{~cm}$ from the tip of medial or the lateral malleolus. ${ }^{14,15}$

There are numerous causes of injury to the ankle, heel, and proximal foot. In our study, the most common cause (63.3\%) was wheel spoke injury. In a developing country like Pakistan, these types of injuries are quite common due to the increased use of motorbikes for conveyance. The feet of rear passenger (children) who are unable to reach the foot-supports are frequently observed hanging insecurely at the level of the spoke. As a result, entanglement is possible, as it is commonly the case when a child loses attention or when a motorbike hits a deep hole and the foot is forced into the spoke of wheel. The injury of the right foot is more common as there are protective chain guards on the left side. ${ }^{16}$

Although free flap is more reliable reconstructive option for such defects, we preferred reverse flow sural artery flap as it is easy, less time consuming, and does not require a microsurgery expert team. The hind foot defects of variable dimensions were covered with RSAF. The donor defect was resurfaced with partial-thickness skin graft in all cases as the donor defects were larger than $3 \mathrm{~cm}$. Although aesthetically it is an unsatisfactory, but 
considering the hind foot a problematic area to heal, it is an acceptable choice for such wounds.

Formerly there are few studies regarding the use of RSAF in the pediatric age group with so much versatility in the dimensions of wounds. We used this flap in 30 children with a success rate of $86.7 \%$. In an other study Furrukh et al. ${ }^{10}$ used this flap in 16 children with complete loss of flap in one case. Grandjean et al. ${ }^{1}$ used this flap in 20 children with a success rate of $80 \%$. In a case series reported by Fathi et al. 17 they designed S-shaped sural fasciocutaneous flap in children but in that series all the patients were having wounds on the heel. Contrary to that in our study multiple areas were covered including heel, ankle, and proximal foot.

In our study, we took the pivot point $5 \mathrm{~cm}$ proximal to the lateral malleolus while Mishra B ${ }^{18}$ performed the sural flap by taking pivot point $7 \mathrm{~cm}$ proximal to tip of the lateral malleolus. Contrary to that, Ebrahiem et al. ${ }^{14}$ performed the sural flaps successfully by taking pivot points 4,3 , and $2 \mathrm{~cm}$ from the lateral malleolus.

One of the most alarming complications of the sural flap is venous congestion. To avoid this complication, Sugg et al. ${ }^{15}$ modified their flap technique by increasing the pedicle width to $4 \mathrm{~cm}$ along with keeping the pedicle skin intact. They observed a significant decrease in venous congestion from $42 \%$ to $0 \%$. In our study, we also kept the pedicle width at least $4 \mathrm{~cm}$ in all cases and the results were satisfactory. Mahipathy et al. ${ }^{19}$ observed similar results in their study by designing the sural flap with a pedicle width of $4 \mathrm{~cm}$ in terms of flap survival and venous congestion as compared to the pedicle width of $3 \mathrm{~cm}$. Recently, Agarwal et al. 20 employed a technique of arteriovenous supercharging using a short saphenous vein to circumvent distal flap necrosis due to venous congestion with satisfactory results.

\section{CONCLUSION}

Foot, heel, and ankle injuries are considered one of the most problematic injuries to manage. The reverse sural artery flap is versatile in terms of its reliability and efficacy and a method of choice in reconstructing soft-tissue defects of the proximal foot and heel in children, especially in those set-ups where microsurgical facilities are not available. The flap is easy to dissect, has robust blood supply and does not sacrifice any major blood vessel of the leg. It is recommended that if flap pedicle width is kept at least $4 \mathrm{~cm}$ along with pedicle skin intact, the problem of venous congestion and distal flap necrosis can be avoided thus improving the complete flap survival rate.

\section{REFERENCES}

1. Grandjean A, Romana C, Fitoussi F. Distally based sural flap for ankle and foot coverage in children. Orthop Traumatol Surg Res. 2016;102(1):111-6.

2. Singh K, Rohilla R, Singh R, Singh S, Singh B, Tanwar M. Outcome Of Distally Based Sural Artery Flap For Distal Third Of Leg And Foot Defects. J Ayub Med Coll Abbottabad. 2017;29(3):462-5.

3. Ciofu RN, Zamfirescu DG, Popescu SA, Lascar I. Reverse sural flap for ankle and heel soft tissues reconstruction. J Med Life [Internet]. 2017;10(1):94-8.
4. Ponten B. The fasciocutaneous flap. Its use in soft tissue defects of the lower leg. Br J Plast Surg 1981;34:215-20

5. Donski PK, Fogdestam I. Distally based fasciocutaneous flap from the sural region. Scand J Plast Reconstr Surg. 1983;17:191-6.

6. Masquelet AC, Romana MC, Wolf G. Skin island flaps supplied by the vascular axis of the sensitive superficial nerves: anatomic study and clinical experience in the leg. Plast Reconstr Surg. 1992;89:1115-20.

7. Jecan C, Goleanu V, Răducu L, Tomescu L, Hernic D, Lascãr I. The Distally Based Superficial Sural Artery Angiosome Flap Concept: Anatomy, Indications, Surgical Technique, Results, Complications and Technical Aspects to Minimize Complications. Mod Med. 2015;1;(22):213-23.

8. Jovanovic $M$, Janjić $Z$, Komarcevic $A$, Jovanović $V$, Marinković M, Tomic M. Neurocutaneous flaps for soft tissue reconstruction of the knee, lower leg, ankle and foot: Clinical experience with 32 patients. Vojnosanit Pregl. 2017;1(76):139.

9. Aydin OE, Tan O, Kuduban SD, Barin EZ. Nerve sparingdistally based sural flap. Microsurgery 2011; 31(4):276-280

10. Mahmood F, Mehrose MY, Tasneem S, Mahmood N, Raza A. Distally based superficial sural artery flap for foot and ankle reconstruction in children. $J$ Ayub Med Coll Abbottabad. 2011;23(4):40-42

11. Zheng L, Zheng J, Dong ZG. Reverse sural flap with an adipofascial extension for reconstruction of soft tissue defects with dead spaces in the heel and ankle. Eur $\mathrm{J}$ Trauma Emerg Surg [Internet]. 2016;42(4):503-11.

12. Luo Z, Ni J, Lv G, Wei J, Liu L, Peng P, Dong Z. Utilisation of distally based sural fasciocutaneous flaps in lower extremity reconstruction: a single-centre experience with 88 paediatric patients. J Orthop Surg Res. 2021;13;16(1):52.

13. Kapadia A, Cheruvu VR, John JR, Tripathy S, Sharma RK. Reconstruction in pediatric orthopedic trauma: the role of primary cross leg flap cover. J Pediatr Orthop B. 2017 Mar;26(2):172-8.

14. Ebrahiem AA, Manas RK, Vinagre G. Distally Based Sural Artery Peroneus Flap (DBSPF) for Foot and Ankle Reconstruction. Plast Reconstr surgery Glob open. 2017;5(4):e1276.

15. Sugg KB, Schaub TA, Concannon MJ, Cederna PS, Brown DL. The Reverse Superficial Sural Artery Flap Revisited for Complex Lower Extremity and Foot Reconstruction. Plast Reconstr surgery Glob open. 2015;3(9):e519-e519.

16. Agu T. Motorcycle spokes entrapment foot injuries: Prevalence, and pattern of presentation in a private orthopedic and trauma center, Southeast Nigeria; A 10-year retrospective analysis. African J Trauma [Internet]. 2017; 6 (1): 6-10.

17. Fathi HR, Fathi M, Javid MJ. S-shaped reverse sural flap for reconstruction of tissue defect on heel. Burns \& trauma. 2013 Vol.1: 39-43.

18. Mishra B. Extended reverse sural flap for lower limb coverage. J. Evid. Based Med.Healthc. 2017;4(93): 57335737.

19. Mahipathy SRRV, Ranganathan S, Murugesan S, Durairaj AR, Sundaramurthy N, Muthu S. A Clinical Study on Islanded Reverse Sural Artery Flap for the Reconstruction of Defects over the Lower Third of Leg and Foot. J Clinical and Diagnostic Research. 2017;11(12):1-6

20. Agarwal P, Sharma D, Kukrele R. Arteriovenous supercharging: A novel approach to improve reliability of the distally based sural flap. Trop Doct [Internet]. 2021 May 31;00494755211020854. Available from:https://doi.org. 